\title{
Pengaruh Variasi Konsentrasi Starter dan NPK terhadap Kadar Etanol Hasil Fermentasi dan Destilasi Nira Aren
}

\section{Effect of NPK and Starter Concentration Variation on Ethanol Content Result of Palm Sap Fermentation and Distillation}

\author{
Ansar $^{1 *}$, Guyub Mahardian Dwi Putra ${ }^{1}$, Sirajudin Haji Abdullah ${ }^{1}$, Marsha Sylvia Siahaya² \\ ${ }^{1}$ Dosen Program Studi Teknik Pertanian, Fakultas Teknologi Pangan dan Agroindustri, Universitas Mataram \\ ${ }^{2}$ Alumni Program Studi Teknik Pertanian, Fakultas Teknologi Pangan dan Agroindustri, Universitas Mataram \\ *E-mail: ansar72@unram.ac.id
}

Diterima: 28 Agustus 2019; Disetujui: 21 November 2019

\begin{abstract}
ABSTRAK
Kebutuhan bahan bakar selalu meningkat seiring dengan peningkatan jumlah kendaraan bermotor, sehingga dibutuhkan alternatif energi pengganti bahan bakar yang ramah lingkungan. Tanaman aren (Arenga pinnata MERR) memiliki sumber gula yang dapat diolah menjadi etanol dengan proses fermentasi. Faktor pembentuk kadar etanol adalah penambahan starter dan nutrisi. Oleh karena itu, tujuan penelitian ini adalah melakukan variasi konsentrasi starter dan NPK untuk mengetahui pengaruhnya terhadap kadar etanol hasil fermentasi dan destilasi nira aren. Starter yang digunakan adalah Saccharomyces Cerevisiae dengan variasi 2,5; 5,0; dan 7,5 ml dengan penambahan NPK 19 gram. Fermentasi dilakukan selama 3 dan 6 hari, kemudian didestilasi menggunakan suhu kondensor $25^{\circ} \mathrm{C}$. Hasil penelitian menunjukkan bahwa fermentasi hari ke-3 diperoleh kadar etanol tertinggi 45,67\% pada konsentrasi starter 2,5\% dan terendah $40,66 \%$ pada starter 5,0\%, sedangkan untuk fermentasi hari ke-6 kadar etanol tertinggi 45,70\% pada konsentrasi starter 7,5 $\mathrm{mL}$ dan terendah $41,27 \%$ pada starter $5,0 \%$. Pada perlakuan penambahan NPK, kadar etanol tertinggi $45,00 \%$ dan terendah 41,67\%. Sedangkan pada perlakuan tanpa penambahan NPK diperoleh kadar etanol tertinggi 68,33\% dan terendah $51,67 \%$. Hal ini menunjukkan bahwa penambahan NPK pada proses fermentasi tidak memberikan pengaruh yang signifikan terhadap kadar etanol.
\end{abstract}

Kata Kunci: destilasi; fermentasi; kadar etanol; nira aren; NPK

\begin{abstract}
The amount of fuel needs is increasing as along as the increase the number of vehicles, so is being needed the fuels with eco-friendly. Palm sap (Arenga pinnata MERR) contains sugar that it can be processed into ethanol with fermentation. Factors forming ethanol levels are add starter and nutrient. Therefore, the purpose of this study is conducted starter concentrate variety and NPK to determine their influence to ethanol content of fermented and palm sap distillation. The starter used is Saccharomyces Cerevisiae with a variation of 2.5; 5.0; and $7.5 \mathrm{ml}$ with the addition of NPK is 19 grams. The fermentation was conducted for 3 and 6 days, was then distilled used condenser temperature $25^{\circ} \mathrm{C}$. The results showed that the $3 \mathrm{rd}$ day fermentation obtained the highest ethanol content of $45.67 \%$ at $2.5 \%$ starter concentration and the lowest $40.66 \%$ at $5.0 \%$ starter, while for the 6th day fermentation the highest ethanol content was $45.70 \%$ at $7.5 \mathrm{~mL}$ starter concentration and the lowest $41.27 \%$ at $5.0 \%$ starter. In the addition of NPK treatment, the highest ethanol content was $45.00 \%$ and the lowest was $41.67 \%$. While the treatment without the addition of NPK obtained the highest ethanol content of $68.33 \%$ and the lowest of $51.67 \%$. This shows that the addition of NPK in the fermentation process did not have a significant effect on ethanol content.
\end{abstract}

Keywords: distillation; fermentation; ethanol content; palm sap; NPK

\section{PENDAHULUAN}

Dewasa ini persediaan bahan bakar fosil semakin menurun, sementara permintaan dan kebutuhan bahan bakar semakin meningkat yang disebabkan dengan banyaknya penggunaan kendaraan bermotor. Dengan demikian, masyarakat harus terus berupaya untuk mencari alternatif pengganti bahan bakar yang sifatnya terbarukan dan bahan bakunya dapat tersedia sepanjang tahun. Indonesia memiliki potensi tanaman aren (Arenga pinnata MERR) yang cukup besar. Sentra pertanaman aren meliputi 14 provinsi dengan perkiraan total areal seluas 60.428 ha (Effendi, 2010).

Pohon aren adalah tanaman yang sudah lama dikenal sebagai sumber gula yang terdapat dalam air sadapannya berupa nira (Lempang, 2012, Ansar dkk., 2019). Kandungan gula pada nira aren yang berkisar antara 6-16\% (Victor dan Orsat, 2018). Apabila dibudidayakan dengan baik, maka jumlah tanaman aren setiap hektar dapat mencapai 156 pohon. Jika yang berproduksi 50\% dari populasi, maka produksi nira dapat mencapai 210.600 liter/hektar/tahun (Lempang, 2012). Rata-rata setiap10 liter nira dapat menghasilkan 3,5 liter etanol. Jadi dalam 1 hektar tanaman aren dapat menghasilkan 73.710 liter etanol. Apabila berproduksi dengan baik, maka potensi etanol aren per tahun dapat mencapai 2 juta kilo liter (Marsigit, 2014).

Salah satu upaya yang dapat dilakukan untuk menghasilkan etanol dari nira aren ini adalah melalui proses fermentasi dan destilasi (Ansar dan Nazaruddin, 
2019). Destilasi merupakan suatu metode pemisahan bahan kimia berdasarkan perbedaan kecepatan penguapan bahan (Zhang dkk., 2016). Pada proses destilasi, campuran zat dididihkan, sehingga menguap dan uap ini kemudian didinginkan kembali ke dalam bentuk cairan. Zat yang memiliki titik didih lebih rendah akan menguap terlebih dahulu (Fahrizal dkk., 2013).

Selama proses fermentasi diperlukan starter yang dapat mempercepat proses terbentuknya kadar etanol di dalam larutan. Menurut Thato dkk., (2014) konsentrasi starter yang terlalu sedikit dapat menyebabkan waktu fermentasi berjalan lambat, sedangkan konsentrasi starter yang terlalu tinggi dapat menyebabkan terlalu banyak alkohol yang terkonversi pada saat awal proses dan banyak glukosa yang belum terkonversi. Starter yang banyak digunakan untuk proses fermentasi adalah ragi fernipan (Saccharomyces cerevisiae) dan NPK cair.

Berdasarkan beberapa argumentasi yang telah disebutkan di atas, maka perlu dilakukan penelitian tentang variasi konsentrasi starter dan NPK yang optimal untuk menghasilkan kadar etanol yang tinggi dari fermentasi dan destilasi nira aren.

\section{METODOLOGI}

Bahan yang digunakan dalam penelitian ini adalah starter dari ragi fernipan dan NPK cair, sedangkan peralatan yang digunakan adalah seperangkat alat destilasi berkapasitas $1000 \mathrm{ml}$ (Gambar 1), termometer, termodigital, desikator, piknometer, dan tabung erlenmyer.

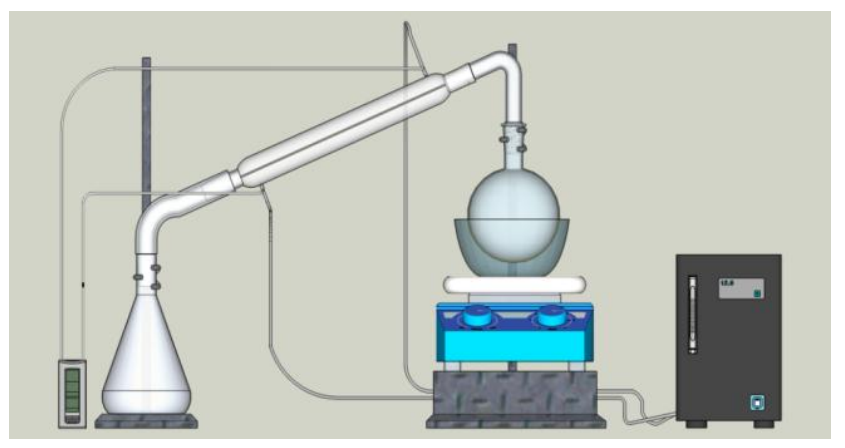

Gambar 1. Sketsa alat destilasi

Parameter penelitian yang diamati adalah lama proses fermentasi dan destilasi, volume hasil destilasi, dan persentase hasil destilasi. Penelitian dilaksanakan dengan tahapan sebagai berikut.

\section{Penyiapan bahan baku}

Nira segar yang sudah disadap langsung diambil dari petani sebanyak 5 liter tanpa menggunakan bahan pengawet. Disiapkan pula beberapa bahan tambahan lainnya seperti ragi fernipan dan NPK cair.

\section{Proses pembuatan starter}

Proses pembuatan starter dilakukan dengan mengaktifkan starter selama 24 jam. Pembuatan starter dilakukan dengan cara memasukkan $200 \mathrm{ml}$ nira aren segar yang dicampur dengan 10 gram ragi fernipan ke dalam gelas kaca, kemudian ditutup rapat sampai tidak ada udara yang masuk selama $1 \times 24$ jam. Selanjutnya disimpan dalam ruangan untuk menunggu proses selanjutnya.

\section{Proses Fermentasi}

Proses fermentasi dilakukan dengan cara dimasukkan $300 \mathrm{ml}$ nira segar ke dalam wadah, kemudian ditambahkan 3 variasi starter yang berbeda yaitu 2,5; 5,0; dan 7,5 ml kemudian ditutup rapat agar fermentasi berjalan secara anaerob. Proses fermentasi selanjutnya adalah penambahan NPK sebanyak 19 gram ke dalam masingmasing gelas kaca tersebut guna mengetahui pengaruhnya terhadap perolehan kadar etanol. Lama fermentasi yang digunakan adalah 3 dan 6 hari.

\section{Destilasi awal}

Destilasi awal dilakukan dengan menggunakan alat destilasi secara langsung tanpa pengaturan suhu. Waktu yang digunakan untuk proses destilasi awal ini juga tidak ditentukan, akan tetapi mengacu kepada piknometer ukuran $50 \mathrm{ml}$. Apabila piknometer telah terisi penuh, maka proses destilasi telah selesai.

\section{Destilasi akhir}

Proses destilasi akhir dilakukan menggunakan suhu kondensor $25^{\circ} \mathrm{C}$. Pemisahan kadar etanol dari larutan hasil fermentasi dilakukan dengan cara menjaga suhu pemanas pada titik didih etanol $\left(78^{\circ} \mathrm{C}\right)$, sehigga kadar etanol terlebih dahulu menguap. Hasil penguapan dialirkan ke pipa dan terkondensasi, kemudian kembali lagi menjadi etanol cair.

Wadah pemasakan etanol menggunakan aluminium dengan metode steam bantuan fluida cair (minyak goreng). Metode steam bertujuan agar suhu pemanas menjadi stabil dan tidak mudah berubah secara drastis pada suhu $100^{\circ} \mathrm{C}$. Suhu panas pada minyak diukur menggunakan termometer.

\section{Hasil destilat}

Hasil destilat ditampung yang keluar dalam Erlenmeyer, kemudian diukur volume destilat dan persentase total kadar etanol dari nira aren.

Perhitungan kadar etanol dilakukan dengan metode berat jenis, dimana berat jenis sampel dikonversi ke persentase kadar etanol menggunakan tabel konversi berikut.

Tabel 1. Konversi berat jenis dan kadar etanol (Lees, 1975).

\begin{tabular}{cccc}
\hline $\begin{array}{c}\text { Berat jenis } \\
\text { larutan } \\
\text { etanol }\end{array}$ & $\begin{array}{c}\text { Kadar } \\
\text { etanol } \\
(\% \mathrm{v} / \mathrm{v})\end{array}$ & $\begin{array}{c}\text { Berat jenis } \\
\text { larutan } \\
\text { etanol }\end{array}$ & $\begin{array}{c}\text { Kadar } \\
\text { etanol } \\
(\% \mathrm{v} / \mathrm{v})\end{array}$ \\
\hline 1,000 & 0,00 & 0,9978 & 1,48 \\
0,9999 & 0,07 & 0,9977 & 1,54 \\
0,9998 & 0,13 & 0,9976 & 1,61 \\
0,9997 & 0,20 & 0,9975 & 1,68 \\
0,9996 & 0,26 & 0,9974 & 1,75 \\
0,9995 & 0,33 & 0,9973 & 1,81 \\
0,9994 & 0,40 & 0,9972 & 1,88 \\
0,9993 & 0,46 & 0,9971 & 1,95 \\
0,9992 & 0,53 & 0,9970 & 2,02 \\
0,9956 & 2,98 & 0,99190 & 5 \\
0,9955 & 3,05 & 0,98569 & 10 \\
0,9954 & 3,12 & 0,98024 & 15 \\
0,9953 & 3,19 & 0,97518 & 20 \\
0,9952 & 3,26 & 0,97008 & 25 \\
0,9951 & 3,33 & 0,96452 & 30 \\
0,9950 & 3,40 & 0,95821 & 35 \\
0,9949 & 3,47 & 0,95097 & 40 \\
0,9948 & 3,54 & 0,94277 & 45 \\
0,9947 & 3,61 & 0,9335 & 50 \\
0,9946 & 3,68 & 0,9235 & 55 \\
& & &
\end{tabular}




\begin{tabular}{cccc}
\hline $\begin{array}{c}\text { Berat jenis } \\
\text { larutan } \\
\text { etanol }\end{array}$ & $\begin{array}{c}\text { Kadar } \\
\text { etanol } \\
(\% \mathrm{v} / \mathrm{v})\end{array}$ & $\begin{array}{c}\text { Berat jenis } \\
\text { larutan } \\
\text { etanol }\end{array}$ & $\begin{array}{c}\text { Kadar } \\
\text { etanol } \\
(\% \mathrm{v} / \mathrm{v})\end{array}$ \\
\hline 0,9945 & 3,76 & 0,9128 & 60 \\
0,9944 & 3,83 & 0,9013 & 65 \\
0,9943 & 3,90 & 0,8892 & 70 \\
0,9942 & 3,97 & 0,8765 & 75 \\
0,9941 & 4,04 & 0,8631 & 80 \\
0,9940 & 4,11 & 0,8488 & 85 \\
0,9939 & 4,18 & 0,8331 & 90 \\
0,9938 & 4,26 & 0,8153 & 95 \\
0,9937 & 4,33 & 0,7935 & 100 \\
\hline
\end{tabular}

\section{Analisis data}

Data hasil penelitian dianalisis menggunakan analisis regresi untuk mengetahui pengaruh starter dan NPK terhadap kadar etanol. Hubungan antara variabel bebas dengan variabel terikat dapat diketahui dengan koefisien determinasi $\left(R^{2}\right)$. Apabila nilai $R^{2}$ mendekati angka 1 berarti terdapat hubungan yang erat.

\section{HASIL DAN PEMBAHASAN}

Berdasarkan hasil perhitungan menggunakan metode berat jenis telah didapatkan kadar etanol tertinggi $68,33 \%$, sedangkan terendah $40,66 \%$ hasil destilasi pada berbagai jenis perlakuan (Gambar 2 dan 3). Hasil ini sejalan dengan penelitian Kismurtono (2012) yang melaporkan bahwa menurunnya kadar etanol disebabkan oleh kandungan etanol dalam larutan telah menguap dan terkondensasi dari pipa ke dalam labu penampung, sehingga bukan lagi dalam bentuk etanol melainkan air, dan menyebabkan kadar air dalam etanol meningkat, jumlahnya pun semakin banyak, namun kadar etanolnya telah berkurang.

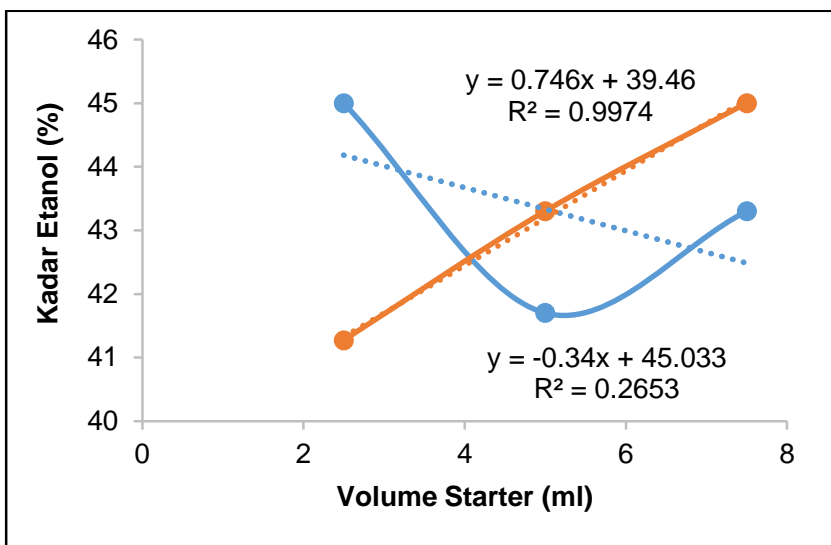

Gambar 2. Hubungan antara volume starter dengan kadar etanol pada fermentasi hari ke-3 dan ke-6 tanpa penambahan NPK.

Dari hasil analisis regresi (Gambar 2) pada fermentasi hari ke-3, didapatkan nilai $R^{2}$ sebesar 0,2653 . Hasil ini menunjukkan bahwa volume starter tidak berpengaruh secara signifikan tehadap kadar etanol yang dihasilkan. Semakin tinggi volume starter, maka terjadi fluktuasi terhadap kadar etanol. Sedangkan hasil analisis regresi pada fermentasi hari ke-6, didapatkan nilai $R^{2}$ yaitu 0,9997. Hasil ini menunjukkan bahwa volume starter berpengaruh secara signifikan terhadap kadar etanol, dimana semakin tinggi volume starter, maka semakin tinggi pula kadar etanol yang dihasilkan.

Dalam penelitian ini juga dilakukan perhitungan kadar etanol yang diperoleh dari hasil fermentasi dengan penambahan NPK. Hasil perhitungan dapat dilihat pada Gambar 3.

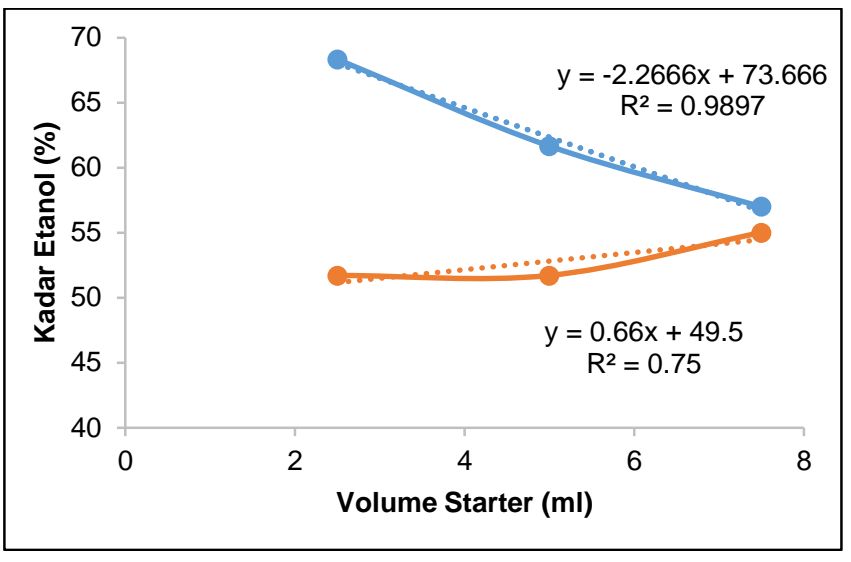

Gambar 3. Hubungan antara volume starter dengan kadar etanol pada fermentasi hari ke-3 dan ke-6 dengan penambahan NPK.

Berdasarkan Gambar 3 diketahui bahwa kadar etanol yang dihasilkan dari fermentasi menggunakan starter tanpa penambahan NPK lebih tinggi dibandingkan dengan perlakuan penambahan NPK. Hal ini menunjukkan bahwa penambahan NPK pada proses fermentasi tidak memberikan pengaruh yang signifikan terhadap kadar etanol yang dihasilkan.

Berdasarkan data yang telah diperoleh diketahui bahwa pada fermentasi hari ke 3 kadar etanol cenderung mengalami penurunan, seperti pada volume starter $2,5 \mathrm{ml}$ menghasilkan kadar etanol 68,33\%. Kemudian pada volume starter 5,0 dan $7,5 \mathrm{ml}$ juga mengalami penurunan menjadi $61,67 \%$ dan $55,01 \%$. Sedangkan pada fermentasi hari ke 6 kadar etanol yang dihasilkan cenderung meningkat seiring dengan banyaknya volume starter, dimana pada volume starter 2,5 dan $5 \mathrm{ml}$ menghasilkan kadar etanol $51,67 \%$, kemudian meningkat menjadi $55 \%$ pada volume starter $7,5 \mathrm{ml}$. Hasil ini sesuai dengan pernyataan Fahrizal dkk. (2013) bahwa dalam proses fermentasi, konsentrasi enzim yang terlalu sedikit dapat menyebabkan waktu fermentasi berjalan lambat. Sedangkan konsentrasi enzim yang terlalu tinggi dapat menyebabkan terlalu banyak etanol yang terkonversi pada saat awal proses dan banyak glukosa yang belum terkonversi. Hal ini menyebabkan keaktifan enzim terhambat dan proses fermentasi menjadi lebih lama.

Lebih lanjut Tan dkk. (2015) telah melaporkan bahwa semakin tinggi konsentrasi starter yang digunakan, maka semakin tinggi pula kadar etanol yang dihasilkan. Hal ini sesuai dengan hasil perhitungan kadar etanol pada fermentasi hari ke-6, dimana seiring dengan banyaknya konsentrasi starter, maka kadar etanol semakin meningkat. Sedangkan pada fermentasi hari ke 3 kadar etanol cenderung mengalami penurunan. Hal ini diduga terjadi karena volume starter yang digunakan berlebihan, sementara waktu fermentasi sedikit. Hal yang sama telah diungkap oleh Zhang dkk. (2016) bahwa jika starter yang digunakan berlebihan, maka dapat menghambat proses fermentasi atau terjadi fase pertumbuhan lambat.

Penelitian yang sama juga dilakukan oleh Trisasiwi dkk. (2009) bahwa lama fermentasi yang paling optimal untuk menghasilkan etanol menggunakan yeast saccharomyces cerevisiae adalah 3 hari. Jika waktu fermentasi dilakukan lebih dari 3 hari, kadar etanol yang dihasilkan semakin berkurang. Awalnya semakin lama waktu fermentasi, kadar etanol yang dihasilkan juga semakin tinggi. Akan tetapi 
setelah kondisi optimum tercapai, kadar etanol yang didapatkan cenderung mengalami penurunan.

Hal ini disebabkan karena ketersediaan glukosa di dalam larutan nira aren sudah mulai sedikit. Selain itu juga terjadi reaksi lanjut dari etanol, sehingga etanol yang diperoleh menurun seiring bertambahnya waktu fermentasi. Reaksi lanjut ini disebabkan teroksidasinya etanol menjadi asam asetat. Laju degradasi glukosa menjadi etanol lebih kecil dibandingkan laju oksidasi etanol menjadi asam asetat, sehingga kadar etanol yang dihasilkan semakin menurun. Dalam penelitiannya, Bekmuradov dkk. (2014) juga mengatakan bahwa dibutuhkan waktu fermentasi yang tepat untuk proses fermentasi etanol agar didapatkan konsentrasi etanol dengan jumlah yang tinggi.

Faktor lain yang mempengaruhi persentase kadar etanol suatu senyawa adalah berat jenis. Dari hasil pengukuran kadar etanol menggunakan metode berat jenis menunjukkan bahwa ketika berat jenis larutan etanol semakin kecil, maka kadar etanol di dalam larutan tersebut semakin besar. Hal ini disebabkan oleh etanol mempunyai berat jenis lebih kecil dari air, sehingga semakin kecil berat jenis larutan berarti jumlah kadar etanol semakin banyak. $\mathrm{Hal}$ ini sejalan dengan penelitian yang dilakukan oleh Anam dkk. (2013), bahwa kadar etanol berbanding terbalik dengan berat jenis etanol yang dihasilkan. Ini terjadi karena berat jenis etanol pada kondisi standar adalah $0,789 \mathrm{~g} / \mathrm{cm}^{3}$, sedangkan berat jenis air adalah $1 \mathrm{~g} / \mathrm{cm}^{3}$, sehingga semakin besar berat jenis etanol yang dihasilkan berarti semakin banyak kandungan air dalam produk tersebut.

Banyaknya kandungan air dalam etanol menyebabkan penurunan kadar kemurnian etanol. Adapun rata-rata berat jenis tertinggi etanol nira aren adalah $0,9454 \mathrm{~g} / \mathrm{cm}^{3}$, sedangkan terendah adalah $0,9331 \mathrm{~g} / \mathrm{cm}^{3}$.

Kadar etanol yang dihasilkan dari proses destilasi adalah etanol derajat teknis (technical grade etanol), yaitu etanol berkadar $70-95 \%$. Teori yang dikemukakan oleh Setiawan (2019) bahwa persyaratan etanol sebagai FGE (fuel grade etanol) yaitu berkadar $99 \%$ atau lebih. Dengan mengetahui kualitas etanol ini, maka diketahui bahwa etanol yang dihasilkan masih perlu didestilasi lebih lanjut untuk menghasilkan etanol derajat teknis.

Dari Gambar 3 juga terlihat bahwa kadar etanol tertinggi yaitu $68,33 \%$ diperoleh dari fermentasi pada hari ke-3 dengan volume starter $2,5 \mathrm{ml}$, sedangkan kadar etanol terendah sebesar $51,67 \%$ diperoleh dari fermentasi pada hari ke-6 dengan volume starter 2,5 dan $5 \mathrm{ml}$. Hal ini menunjukkan bahwa penambahan NPK pada proses fermentasi tidak memberikan pengaruh yang signifikan terhadap kadar etanol yang dihasilkan.

\section{KESIMPULAN}

Kadar etanol pada fermentasi hari ke-3 tertinggi 45,67\% diperoleh pada penggunaan starter $2,5 \mathrm{~mL}$ dan terendah $40,66 \%$ pada starter $5,0 \%$, sedangkan untuk fermentasi hari ke-6 tertinggi $45,70 \%$ pada penggunaan starter $7,5 \mathrm{~mL}$ dan terendah $41,27 \%$ pada starter $5,0 \%$. Hasil ini menunjukkan bahwa semakin tinggi penggunaan starter, semakin besar perolehan kadar etanol.

Kadar etanol pada perlakuan penambahan NPK tertinggi $45,00 \%$ dan terendah $41,67 \%$, sedangkan pada perlakuan tanpa penambahan NPK diperoleh kadar etanol tertinggi $68,33 \%$ dan terendah $51,67 \%$. Hal ini menunjukkan bahwa penggunaan NPK pada proses fermentasi tidak berpengaruh secara signifikan terhadap perolehan kadar etanol.

\section{DAFTAR PUSTAKA}

Anam. S., Tabbssum, M.R., Rashid, U., Ibrahim, M., Gill, S.S., \& Mehmood, M.A. (2013). Marine macro algae ulva: a potential feed-stock for bioethanol and biogas production. Asian Journal and Agriculture Biology, 1(3): 155-163.

Ansar \& Nazarudin (2019). Metode Pembuatan Biofuel dari Nira Aren. Penerbit Kelompok Intermediasi Alih Teknologi, Mataram.

Ansar, Nazarudin, \& Azis, A.D. (2019). Pengaruh suhu dan lama penyimpanan terhadap perubahan $\mathrm{pH}$ dan warna nira aren (Arenga pinnata Merr) setelah penyadapan. Jurnal Teknik Pertanian Lampung, 8(1): 40- 48

Bekmuradov, V., Luk, G., \& Luon, R. (2014). Comparative ethanol productivities of two different recombinant fermenting strains on source-separated organic waste. International Journal of Engineering Research and Applications, 4(1): 77-82.

Effendi, D.S. (2010). Prospect of aren tree development (arenga pinnata MERR) to supporting bioethanol need in Indonesia. Perspektif, 9(1): 36-46.

Fahrizal, F., Abubakar, Y., Muzaifa, M., \& Muslim, M. (2013). The effects of temperature and length of fermentation on bioethanol production from arenga plant (arenga pinnata MERR). International Journal on Advanced Science, Engineering, Information Technology, 3(1): 55-59.

Kismurtono, M. (2012). Fed-batch alcoholic fermentation of palm juice (Arenga pinnata MERR): Influence of the feeding rate on yeast, yield and productivity. International Journal of Engineering \& Technology. 2(5): 795-799.

Marsigit, W. (2005). Food additive application on the quality of palm sugar at Processing Center in Bengkulu. Research Journal UNIB, 11(1): 42-48.

Setiawan, S. (2019). Penjelasan energi biofuel serta jenisjenisnya. Diakses 8 Mei 2019. https://www.guru pendidikan.co.id/ penjelasan-energi-biofuel-serta-jenisjenisnya.

Tan, L., Sun, Z.Y., Okamoto, S., Takaki, M., Morimura, S., Kida, K., \& Tang, Y.Q. (2015). Production of ethanol from raw juice and thick juice of sugar beet by continuous ethanol fermentation with flocculating yeast strain KF-7. Biomass and Bioenergy, 81(1): 256-272. doi:10.1016/j.biombioe.2015.07.019.

Thato, H, Dash, P.K., Mohapatra, S, \& Swain, M.R. (2014). Bioethanol production from tuber crops using fermentation technology: a Review. International Journal of Sustainable Energy. 35(5): 443-468.

Trisasiwi, W., Asnani, A., \& Setyawati, A. (2009). Pembuatan Bioetanol dari Nira Nipah (Nipha fruticons) Menggunakan Bakteri Zymomonas mobilis. Hibah Penelitian Strategis Nasional. Direktorat Jenderal Pendidikan Tinggi Kementerian Pendidikan Nasional. Universitas Jenderal Soedirman. Purwokerto.

Victor, I., \& V. Orsat. (2018). Characterization of arenga pinnata (palm) sugar. Sugar Tech, 20(1): 105-109. doi: 10.1007/s12355-017-0537-3

Zhang, Q., Weng, C., Huang, H., Achal, V., \& Wang, D. (2016). Optimization of bioethanol production using whole plant of water hyacinth as substrate in simultaneous saccharification and fermentation process. Frontiers in Microbiology, 6(1):1-9. doi:10.3389/fmicb.2015.01411. 